\title{
Why the Neighborhood Social Environment Is Critical in Obesity Prevention
}

\author{
Shakira F. Suglia, Rachel C. Shelton, Amber Hsiao, \\ Y. Claire Wang, Andrew Rundle, and Bruce G. Link
}

\begin{abstract}
The continuing obesity epidemic in the USA calls for the examination of antecedents to the well-known risk factors of physical activity and diet. The neighborhood built environment has been extensively studied in relation to obesity noting an increased risk of development and prevalence of obesity in relation to numerous built environment characteristics (lack of green spaces, higher number of fast food restaurants, low walkability indices). The neighborhood social environment, however, has been less extensively studied but is perhaps an equally important component of the neighborhood environment. The neighborhood social environment, particularly constructs of social capital, collective efficacy, and crime, is associated with obesity among both adults and children. Several studies have identified physical activity as a potential pathway of the neighborhood social environment and obesity association. Further work on social networks and norms and residential segregation, as well as the examination of dietary behaviors and mental health as potential mediating pathways, is necessary. Given the existing evidence, intervening on the neighborhood social environment may prove to be an effective target for the prevention on obesity. Intervention studies that promote healthy behaviors and prevent obesity while addressing aspects of the neighborhood social environment are necessary to better identify targets for obesity prevention.
\end{abstract}

KEYWORDS Neighborhood safety, Social capital, Social cohesion, Neighborhood disadvantage, Residential segregation, Physical activity, Obesogenic behaviors

Abbreviations: BMI - Body mass index

\section{INTRODUCTION}

Neighborhoods exist in spaces that either have or do not have parks, sidewalks, and bike paths. Stores, restaurants, theaters, and work places can be located within walking distance or else require a car, taxi, train, or bus to access. Dimensions such as these have obvious relevance to obesity prevention. Over the past decade, links between features of the neighborhood built environment and obesity have been widely reported, to the extent that Healthy People 2020 includes goals for

Suglia and Rundle are with the Department of Epidemiology, Mailman School of Public Health, Columbia University, 722 West 168th St., New York, NY 10032, USA; Shelton is with the Department of Sociomedical Sciences, Mailman School of Public Health, Columbia University, New York, NY, USA; Hsiao and Wang are with the Department of Health Policy and Management, Mailman School of Public Health, Columbia University, New York, NY, USA; Link is with the University of California Riverside, 900 University Avenue, Riverside, CA 92521, USA.

Correspondence: Shakira F. Suglia, Department of Epidemiology, Mailman School of Public Health, Columbia University, 722 West 168th St., New York, NY 10032, USA. (E-mail: sfs2150@cumc.columbia.edu) 
neighborhood built environment interventions to support physical activity. A less intensely studied, but equally or perhaps more important aspect of neighborhoods is the potential role that the social context of a neighborhood plays in shaping obesity risk.

Building on definitions provided by Diez-Roux and McNeill, ${ }^{1,2}$ the neighborhood social environment is considered to include the sociodemographic composition of the neighborhood and its residents as well as the "relationships, groups, and social processes that exist between individuals who live in a neighborhood". ${ }^{3-6}$ The examination of the neighborhood social environment in relation to health has been examined as a set of features that comprise the "social context" of the neighborhood, such as social cohesion, social capital, collective efficacy, social norms, neighborhood crime and safety, poverty, and segregation. The existing literature is limited in that only some features of the social environment have been explored for their association with obesogenic behaviors, with much of the work focusing on physical activity.

The most frequently examined neighborhood social characteristic is neighborhood poverty, which has been associated with obesity in numerous studies. ${ }^{7-9}$ Neighborhoods with poor community-level or government economic resources often have fewer resources related to the built environment, including poor recreational facilities, supermarkets, lack of functioning sidewalks, and limited access to parksall factors that may contribute to obesity. ${ }^{10}$ In addition, neighborhood poverty also correlates with poor social environments, including higher crime rates, low aesthetic quality, poor social cohesion and social capital, and increased residential segregation. These factors, outlined below, are also associated with obesity; hence, the effect of neighborhood poverty on obesity may be mediated through its effects on other social characteristics of the neighborhood social environment (e.g., crime, social cohesion, and residential segregation) (Fig. 1). ${ }^{1}$

Lack of neighborhood safety, defined as perceptions of unsafe neighborhoods as well as objectively measured high-crime neighborhoods have been associated with obesity among both adults and children even after adjusting for socioeconomic factors. ${ }^{11-13}$ Several studies have noted associations between crime and perceptions of unsafe neighborhoods and low levels of physical among adults and children, ${ }^{14}$ with several studies noting associations only among women. ${ }^{12,15}$ As women are more often the victims of sexual crimes, they may be more likely to modify their behaviors (i.e., limiting time outdoors engaging in physical activity) if they perceive their environment to be unsafe. ${ }^{14}$ Behavioral changes in response to neighborhood

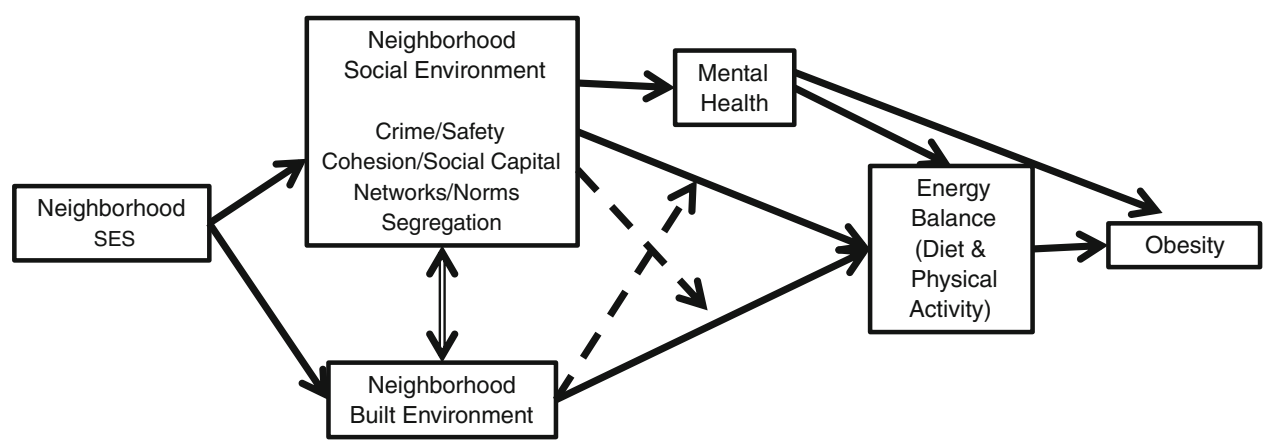

FIG. 1 Conceptual model of the relations between the neighborhood social environment and obesity. Solid lines represent direct relations; dashed lines represent modifiers of direct relations. 
crime may be a pathway through which neighborhood crime impacts obesity. Neighborhood safety and crime may also influence social networks and cohesion among neighborhood residents by limiting opportunities for social interaction and promoting distrust among residents. ${ }^{16}$

Social cohesion and social capital have been negatively associated with BMI and obesity but positively associated with physical activity among both adults and adolescents. ${ }^{8,17,18}$ A positive perception of the neighborhood social environment may increase the likelihood of outdoor physical activity; parents, for example, may be more likely to allow their children to play outside. ${ }^{19}$ Increased levels of collective efficacy and social cohesion provide more opportunities for modeling healthy behaviors in a supportive environment in addition to preventing deterioration of the physical environment (i.e., trash, street lights, graffiti) and promoting safety. ${ }^{19,20}$

In disadvantaged neighborhoods, having poor quality built environments-whichs limit an individual's potential for physical activity and access to healthy foods-there may also be a lack of structural opportunities (i.e., safe parks) for social interaction, resulting in limited social networks. While evidence of the influence of social networks on obesity and related behaviors is typically not limited to the neighborhood environment, they are still important to consider, as social networks within a neighborhood may be highly visible and influential, and people may form close bonds with neighbors or choose to live in proximity to family and friends. ${ }^{21,22}$ Social ties may also influence healthy eating or physical activity through the provision of social support or the establishment of social norms ${ }^{23}$ or through a sense of attachment and connectedness to resources and goods that support healthy behaviors, ${ }^{1}$ both of which may take place within a neighborhood context. Social norms could relate to beliefs about ideal body size, preference for being non-obese, beliefs about physical activity or certain foods, and stigma associated with a person's being overweight or obese. ${ }^{24}$ Norms of behavior (eating, physical activity) are particularly important to understand in the context of the neighborhood environment where people are in close contact with one another and are able to observe or model certain behaviors that may spread. This is particularly relevant when considering the role of racial residential segregation on obesity.

Among African Americans, residential racial segregation has been associated with higher rates of obesity. ${ }^{25}$ Lower levels of physical activity may be one potential pathway through which residential segregation increases the odds of obesity. ${ }^{26}$ African Americans living in segregated areas have been noted to rate their neighborhoods as less pleasant for physical activity and as having fewer physical activity facilities compared to African Americans living in less segregated areas. $^{27}$ Geographic concentrations of racial/ethnic minorities often co-occur in neighborhoods of concentrated poverty creating economic, infrastructural, and social conditions that support the development of fast food restaurants, limited access to affordable healthy food, and few recreational facilities. ${ }^{28}$ The impact of residential racial segregation on obesity and obesogenic behaviors varies by racial/ ethnic group. Immigrant enclaves often support home country diets and other more healthful lifestyle behaviors thus reducing the risk of obesity. Among Hispanics, findings relating residential segregation and obesity have been inconsistent. ${ }^{29,30}$ Differing levels of acculturation among Hispanic enclaves are likely to account for the noted differences as the health benefits associated with living in a majority Hispanic neighborhood may only be evident among less acculturated Hispanics. ${ }^{31}$ 


\section{FUTURE RESEARCH DIRECTIONS}

While the current literature is not free from inherent limitations of observational studies, there is increasing evidence of an association between features of the neighborhood social environment and obesity. Further research into several key areas would further our understanding of the mechanisms operating behind these associations.

First, future work should focus on the influence of the neighborhood social environment on understudied behaviors, particularly as they relate to dietary intake and stress-coping behaviors. Second, as neighborhood environments are experienced throughout the life course, potential differential effects by life stage should also be considered recognizing that specific age groups may be more vulnerable to the effects of the social environment. Similarly, gender differences should be taken into consideration as men and women, including children and adolescents, may differ in their use of the environment as well as their vulnerability to certain social factors. Third, exploring factors that influence social norms and how they are shared across neighborhoods could inform how to best devise interventions that can maintain change long after the intervention is completed. Fourth, it will be important for future research to disentangle negative effects of residential segregation from potential positive effects on health that have been found among ethnic enclaves. Lastly, while observational studies have shown the neighborhood social environment to be associated with obesogenic behaviors and weight status, further research should focus on testing interventions that would promote the development of a positive social environment and as a consequence improve mental health and well-being, increase physical activity among residents, improve dietary behaviors, and reduce or maintain BMI. Interventions that focus on the development of the built environment for the prevention of obesity could potentially be more fruitful if the social environment is also taken into consideration.

\section{TARGETING THE SOCIAL ENVIRONMENT FOR OBESITY PREVENTION}

In spite of the existing evidence, few obesity prevention interventions have been developed within the context of the neighborhood environment taking advantage of the residents' social capital and social networks. ${ }^{32}$ Promotion of the built environment, particularly through the use of parks and recreational facilitates, would increase the opportunity for interactions with neighbors if it is coupled with interventions that lower crime and promote safety and a sense of security. Doing so would foster cohesion and collective efficacy in a community. ${ }^{19,33}$ For example, through the development of joint use agreements, communities can gain access to school recreational facilities that may otherwise not be available to the public after school hours, thus providing a cost-effective way to share community resources while also increasing opportunities to engage in physical activity. The process of developing such an agreement could aid in the development of social capital within the community; thus, communities that come together to develop a joint use agreement or to design and develop other community resources could result in multiple gains for the community-a gain in a built environment resource, such as a park, and a gain in social efficacy, both of which may address obesity risk behaviors. 
Other promising interventions are, for example, the Safe Routes to School program which promotes walking and bicycling to school by providing safe and accessible routes to school. In addition to promoting the development of sidewalks and bike paths where none exist, the program promotes the involvement of law enforcement to work with community groups and schools.

A focus on improving neighborhood social conditions as a way of promoting physical activity, and likely other positive health outcomes, suggests the need for engagement with municipal agencies, business associations, and civic groups that might not typically self-identify with health promotion. Strategies to improve neighborhood social environments require systems level and multi-sectoral approaches encapsulated in the "Health in All Policies" approach to municipal government, which incorporates health considerations into decision-making across sectors, policy areas, and governmental agencies that typically have not focused on health as a major part of their mission. ${ }^{34}$ Within this framework, policing strategies, street cleaning, graffiti removal, urban forestry, public transit, and zoning can be seen to have impacts on neighborhood social environments that support healthy physical activity and dietary patterns. Budgetary and cost-benefit analyses that are used to fund and prioritize such activities can incorporate potential impacts on neighborhood social environments and health benefits as an output of these municipal activities. In many urban areas, business improvement districts (BIDs) supplement or replace municipal efforts to provide maintenance, security, and garbage removal services and as such may contribute to improving neighborhood social conditions relevant to physical activity. Similarly the efforts of block associations, neighborhood watches, and community associations could be energized and leveraged when their activities are understood as supporting positive health behaviors and outcomes in their communities. Such organizations might not self-identify as being agents of community health, but their potential to improve neighborhood social conditions suggests that they could be part of a larger culture of health.

As an example, the Shape Up Somerville program, a community-based participatory research program to prevent weight gain among young children, engaged a wide variety of community members in the implementation of their multilevel intervention (home, school, and neighborhood). The intervention which at the neighborhood level included a community advisory council, ethnic minority group collaborations, support from local "community champions," walking/pedestrian training, a farmers market initiative, city ordinances on walkability and bikeability, and a fitness fair significantly reduced BMI $z$-scores among children at high risk of obesity. $^{35}$

The few examples that exist of interventions and programs that affect the neighborhood social environment to prevent obesity are all coupled with programs and activities that promote the use of the physical environment. Thus, as noted, addressing both the social and physical environment when designing neighborhood level interventions would be a more promising approach for the effective prevention of obesity at the neighborhood level. Crucial to obesity prevention will be the development of societies that not only value safe and accessible physical spaces that promote overall physical activity but also believe and promote social norms of healthy diets and healthy weight status. Intervening on neighborhood social factors in order to prevent obesity will only have an impact if they are supported by broader social and cultural norms that prioritize and promote health and health behaviors that are closely linked with obesity. 


\section{ACKNOWLEDGMENTS}

We would like to thank the support of the Mailman School of Public Health Obesity Prevention Initiative. We thank Carol A Dreibelbis of the Mailman School of Public Health for her assistance with article editing.

\section{COMPLIANCE WITH ETHICAL STANDARD}

Funding. Dr. Suglia was supported by K01HL103199. Dr. Shelton was supported by a Mentored Research Scholar Grant from American Cancer Society (124793MRSG-13-152-01-CPPB).

\section{REFERENCES}

1. McNeill LH, Kreuter MW, Subramanian SV. Social environment and physical activity: a review of concepts and evidence. Soc Sci Med. 2006; 63(4): 1011-1022.

2. Diez Roux AV, Mair C. Neighborhoods and health. Ann N Y Acad Sci. 2010; 1186: 125145.

3. Carroll-Scott A, Gilstad-Hayden K, Rosenthal L, et al. Disentangling neighborhood contextual associations with child body mass index, diet, and physical activity: the role of built, socioeconomic, and social environments. Soc Sci Med. 2013; 95: 106-114.

4. Sampson RJ, Morenoff JD, Earls F. Beyond social capital: spatial dynamics of collective efficacy for children. Am Sociol Rev. 1999; 64: 633-660.

5. Sampson RJ, Raudenbush SW, Earls F. Neighborhoods and violent crime: a multilevel study of collective efficacy. Science. 1997; 277(5328): 918-924.

6. Yen IH, Syme SL. The social environment and health: a discussion of the epidemiologic literature. Annu Rev Public Health. 1999; 20: 287-308.

7. Nicholson LM, Browning CR. Racial and ethnic disparities in obesity during the transition to adulthood: the contingent and nonlinear impact of neighborhood disadvantage. J Youth Adolesc. 2012; 41(1): 53-66.

8. Carter MA, Dubois L. Neighbourhoods and child adiposity: a critical appraisal of the literature. Health Place. 2010; 16(3): 616-628.

9. Leal C, Chaix B. The influence of geographic life environments on cardiometabolic risk factors: a systematic review, a methodological assessment and a research agenda. Obes Rev. 2011; 12(3): 217-230.

10. Gordon-Larsen P, Nelson MC, Page P, Popkin BM. Inequality in the built environment underlies key health disparities in physical activity and obesity. Pediatrics. 2006; 117(2): 417-424.

11. Fish JS, Ettner S, Ang A, Brown AF. Association of perceived neighborhood safety with [corrected] body mass index. Am J Public Health. 2010; 100(11): 2296-2303.

12. Larson NI, Wall MM, Story MT, Neumark-Sztainer DR. Home/family, peer, school, and neighborhood correlates of obesity in adolescents. Obesity (Silver Spring). 2013; 21(9): 1858-1869.

13. Burdette HL, Wadden TA, Whitaker RC. Neighborhood safety, collective efficacy, and obesity in women with young children. Obesity (Silver Spring). 2006; 14(3): 518-525.

14. Bennett GG, McNeill LH, Wolin KY, Duncan DT, Puleo E, Emmons KM. Safe to walk? Neighborhood safety and physical activity among public housing residents. PLoS Med. 2007; 4(10): 1599-1606. discussion 1607.

15. Bacha JM, Appugliese D, Coleman S, et al. Maternal perception of neighborhood safety as a predictor of child weight status: the moderating effect of gender and assessment of potential mediators. Int J Pediatr Obes. 2010; 5(1): 72-79. 
16. De Jesus M, Puleo E, Shelton RC, Emmons KM. Associations between perceived social environment and neighborhood safety: health implications. Health Place. 2010; 16(5): 1007-1013.

17. Echeverria S, Diez-Roux AV, Shea S, Borrell LN, Jackson S. Associations of neighborhood problems and neighborhood social cohesion with mental health and health behaviors: the multi-ethnic study of atherosclerosis. Health Place. 2008; 14(4): 853-865.

18. Cradock AL, Kawachi I, Colditz GA, Gortmaker SL, Buka SL. Neighborhood social cohesion and youth participation in physical activity in Chicago. Soc Sci Med. 2009; 68(3): 427-435.

19. Halbert $\mathrm{CH}$, Bellamy S, Briggs V, et al. Collective efficacy and obesity-related health behaviors in a community sample of African Americans. J Community Health. 2014; 39(1): 124-131.

20. Carter MA, Dubois L, Tremblay MS, Taljaard M, Jones BL. Trajectories of childhood weight gain: the relative importance of local environment versus individual social and early life factors. PLoS One. 2012; 7(10), e47065.

21. Christakis NA, Fowler JH. The spread of obesity in a large social network over 32 years. N Engl J Med. 2007; 357(4): 370-379.

22. Shelton RC, McNeill LH, Puleo E, Wolin KY, Emmons KM, Bennett GG. The association between social factors and physical activity among low-income adults living in public housing. Am J Public Health. 2011; 101(11): 2102-2110.

23. Berkman LF. Social support, social networks, social cohesion and health. Soc Work Health Care. 2000; 31(2): 3-14.

24. Hruschka DJ, Brewis AA, Wutich A, Morin B. Shared norms and their explanation for the social clustering of obesity. Am J Public Health. 2011; 101(Suppl 1): S295-S300.

25. Corral I, Landrine H, Hao Y, Zhao L, Mellerson JL, Cooper DL. Residential segregation, health behavior and overweight/obesity among a national sample of African American adults. J Health Psychol. 2012; 17(3): 371-378.

26. Lopez R. Black-white residential segregation and physical activity. Ethn Dis. 2006; 16(2): 495-502.

27. Boslaugh SE, Luke DA, Brownson RC, Naleid KS, Kreuter MW. Perceptions of neighborhood environment for physical activity: is it "who you are" or "where you live"? J Urban Health. 2004; 81(4): 671-681.

28. Kwate NO. Fried chicken and fresh apples: racial segregation as a fundamental cause of fast food density in black neighborhoods. Health Place. 2008; 14(1): 32-44.

29. Kershaw KN, Albrecht SS, Carnethon MR. Racial and ethnic residential segregation, the neighborhood socioeconomic environment, and obesity among Blacks and Mexican Americans. Am J Epidemiol. 2013; 177(4): 299-309.

30. Corral I, Landrine H, Zhao L. Residential segregation and obesity among a national sample of Hispanic adults. J Health Psychol. 2014; 19(4): 503-508.

31. Park Y, Neckerman KM, Quinn J, Weiss C, Rundle A. Place of birth, duration of residence, neighborhood immigrant composition and body mass index in New York City. Int J Behav Nutr Phys Act. 2008; 5: 19.

32. Leroux JS, Moore S, Dube L. Beyond the "I" in the obesity epidemic: a review of social relational and network interventions on obesity. J Obes. 2013; 2013: 348249.

33. Prusak L, Cohen D. How to invest in social capital. Harv Bus Rev. 2001; 79(6): 86-93. 147.

34. Rudolph L, Caplan J. Health in all policies: a guide for state and local governments. Washington, DC and Oakland, CA: Public Health Institute; 2013.

35. Economos CD, Hyatt RR, Goldberg JP, et al. A community intervention reduces BMI zscore in children: shape Up Somerville first year results. Obesity (Silver Spring). 2007; 15(5): 1325-1336. 